NBER WORKING PAPER SERIES

\title{
THE IMPORTANCE OF EDUCATION AND SKILL DEVELOPMENT FOR ECONOMIC GROWTH IN THE INFORMATION ERA
}

\author{
Charles R. Hulten \\ Working Paper 24141 \\ http://www.nber.org/papers/w24141 \\ NATIONAL BUREAU OF ECONOMIC RESEARCH \\ 1050 Massachusetts Avenue \\ Cambridge, MA 02138 \\ December 2017
}

I would like to thank Leonard Nakamura and Valerie Ramey for their comments on earlier drafts, as well as the participants at the October 16-17, 2015, NBER/CRIW conference Education, Skills, and Technical Change: Implications for Future U.S. GDP Growth. Remaining errors and interpretations are my responsibility. The views expressed herein are those of the author and do not necessarily reflect the views of the National Bureau of Economic Research.

NBER working papers are circulated for discussion and comment purposes. They have not been peer-reviewed or been subject to the review by the NBER Board of Directors that accompanies official NBER publications.

(C) 2017 by Charles R. Hulten. All rights reserved. Short sections of text, not to exceed two paragraphs, may be quoted without explicit permission provided that full credit, including () notice, is given to the source. 
The Importance of Education and Skill Development for Economic Growth in the Information

Era

Charles R. Hulten

NBER Working Paper No. 24141

December 2017

JEL No. I26,J24,O47

\begin{abstract}
The neoclassical growth accounting model used by the BLS to sort out the contributions of the various sources of growth in the U.S. economy accords a relatively small role to education. This result seems at variance with the revolution in information technology and the emergence of the "knowledge economy", or with the increase in educational attainment and the growth in the wage premium for higher education. This paper revisits this result using "old fashioned" activity analysis, rather than the neoclassical production function, as the technology underlying economic growth. An important feature of this activity-based technology is that labor and capital are strong complements, and both inputs are therefore necessary for the operation of an activity. The composition of the activities in operation at any point in time is thus a strong determinant of the demand for labor skills, and changes in the composition driven by technical innovation are a source of the increase in the demand for more complex skills documented in the literature. A key result of this paper is that the empirical sources-of-growth results reported by BLS could equally have been generated by the activity-analysis model. This allows the BLS results to be interpreted in a very different way, one that assigns a greater importance to labor skills and education.
\end{abstract}

Charles R. Hulten

Department of Economics

University of Maryland

Room 3114, Tydings Hall

College Park, MD 20742

and NBER

hulten@econ.umd.edu 


\section{Introduction}

The rapid advance of information technology and globalization has led to major structural changes in the U.S. economy. The extent of these changes is evident in the decline of manufacturing industry and the rise of selected service-producing sectors shown in Figures 1 and 2. The share of manufacturing in private GDP has been cut in half over the last half century, from 30\% in 1960 to less than 15\% in 2015, and the share of private employment has fallen from around $34 \%$ to $10 \%$. This decline was more than offset by increases in those service sectors that involve “expert” advice, information, or interventions - finance, business and professional, education, health, law, and information services: the share of value added rose from around 13\% to $37 \%$, while the share of employment rose from under $14 \%$ of total private employment to over $40 \% .{ }^{1}$ These shifting patterns reflect, in part, the outsourcing of production to lower-wage countries, labor-saving technical change, and the evolution of demand for different products. ${ }^{2}$ The trends in professional and business organizational services, also shown in Figures 1 and 2, indicate a significant shift in employment within firms toward non-production activities, and reflect the growth of in-firm research and development, product design, and the emergence of sophisticated organizational management systems.

The change in the structure of employment and valued added occurred during a period that also saw a parallel increase in higher-order cognitive and non-cognitive worker skills of the labor force, documented by Autor, Levy, and Murnane (2003) in their path-breaking paper, as well as a significant increase in educational attainment. Moreover, the fraction of the U.S. population 25 years or older with at least a B.A. degree quadrupled (to 32\%) over the period from 1960 to 2015; the fraction of those with at least a high school degree more than doubled (to almost 90\%), according to data from the Census Current Population Survey. Evidence cited in this paper suggests that the upward trends in educational attainment and the demand for more

1 The part of the service sector designated "expert" in Figures 1 and 2 refers to those NAICS industries 51, 52, 54, 55, 56, 61 and 62. (the organization services include NAICS 54, 55, and 56). The statistics shown here are taken from the industry accounts of the Bureau of Economic Analysis. They are expressed as a share of the private economy because the focus of this paper is on innovation, education, and growth accounting in the business sector. The ratio of private to total value added was $87 \%$ in 2015 , and the corresponding ratio for full and part time employees was $86 \%$, so the sectoral estimates are somewhat smaller when expressed as a ratio of the totals. The time series shown in Figure 2 is pieced together from different parts of industry Table 6.5 and is thus subject to some discrepancies.

${ }^{2}$ Haskell et al. (2012) and Autor, Dorn, and Hanson (2013). 
complex cognitive skills are connected to the structural changes in the economy evident in Figures 1 and 2; those service sectors where the employment increase was most pronounced were also those where the high-skill, high-education professions are located. The observed structural shifts are thus consistent with the growth of the knowledge economy.

It is one thing to regard skill development and education as important for the functioning and growth of the economy, but how important are they compared to other factors that influence the growth of GDP? Surprisingly, estimates from the Bureau of Labor Statistics Multifactor Productivity Program suggest that educational attainment may not be as important for economic growth as the recent focus on education and skills implies. The BLS data indicate that changes in the composition of the labor force, largely due to education, accounted for only a small fraction (7\%) of the growth in labor productivity in the U.S. private business sector over the period 1995 to 2007 (the last year before the Great Recession). Robert Solow famously remarked in 1987 that "you can see the computer age everywhere but in the productivity statistics”; in the current context, one might say that we can see the revolution in educational attainment everywhere but in the productivity statistics.

Acemoglu and Autor (2012) have questioned how education can have played only a relatively small role in the growth of the economy, given the knowledge-intensive nature of the information revolution. Indeed, there is a large literature on the importance of education as a source of economic growth and on the importance of skill-biased technical change. However, most of this analysis does not stray far from a production-function formulation of the problem and an emphasis on marginal productivities and factor substitutability.

The approach taken in this paper builds on the contributions of Acemoglu and Autor (2011, 2012), who focus on the role of skills and education at the task and occupations levels of the production process, with the goal of linking the growth in complex non-routine skills to skillbiased technical change. The activity-analysis model of this paper also starts at the micro level of production, but focuses on the substitution possibilities among inputs; the goal is to show how limited substitution possibilities within the production techniques of an activity can lead to a much greater role for skill development and education than that implied by the neoclassical BLS approach, even though both use virtually the same growth accounting methods. The basic idea is that the choice of technique determines the nature of the inputs required, and once a technique is adopted, substitution possibilities among the inputs are typically quite limited (accountants are 
not substitutes for neurosurgeons). The skills necessary for each type of activity come embodied in people, in part via their educational preparation, and access to people with the necessary skills and education becomes a critical factor enabling structural change and economic growth. Conversely, an inadequate supply of skilled workers with the requisite skills can serve as a drag on growth. Education provides a pool of general cognitive and occupational expertise, and in some cases, specific vocational skills, from which firms can draw the workers they need. It is hard to imagine the economy of 2017 operating with a pool of workers in which less than half had a high school degree, as in 1960, and less than $10 \%$ had a college degree.

These points are developed in greater detail in the sections that follow. The Solow neoclassical growth accounting model used by BLS is described in Section II, along with a critique of the theory underpinning its labor force composition adjustment in Section III. This is followed, in Section IV, by the activity-analysis framework proposed in this paper. The fixedproportion nature of the framework is described and illustrated using several examples. This “necessary input” model is contrasted with the aggregate production function approach, with special attention to its implication for skills and education. A sources-of-growth framework based on the activity analysis model is derived, and shown to be essentially equivalent to the neoclassical version of the growth accounting model. This result allows the BLS growth accounting estimates to be given a different interpretation, one that assigns a greater importance to labor skills and education than the conventional approach. The three sections that follow Section IV are empirical, and examine the evidence on the trends in labor and capital to see if they are consistent with the predictions of the activity-analysis framework. Section V traces the growing importance of higher educational attainment, higher order cognitive and non-cognitive skills, and professional occupations and employment over the last half century. Section VI looks at the parallel development in the growth in Information and Communications Technology equipment (ICT) and intangible knowledge capital like R\&D. Sources-of-growth estimates expanded to include intangible capital are presented in Section VII, and interpreted in light of the activity-analysis framework. A final section sums up.

\section{The Neoclassical Growth Accounting Model}

Many factors affect the growth of GDP, including labor and its skills but also capital formation and technical change. Any general assessment of the contribution of labor skills and education 
should therefore be framed in the context of all of the relevant factors. The main empirical framework that does this is the neoclassical growth accounting model developed by Solow (1957) and greatly extended by Jorgenson and Griliches (1967), who laid the groundwork for the official productivity program at the BLS.

Neoclassical growth models share a common feature: they are rooted in the assumption of an aggregate production function relating aggregate outputs to the factor inputs of aggregate labor and capital, with a shift term that allows for changes in the productivity of the inputs: $Y_{t}=$ $F\left(K_{t}, L_{t}, t\right)$. In describing the role of the shift term in the function, Solow states:

"The variable $t$ for time appears in $F$ to allow for technical change. It will be seen that I am using the phrase 'technical change' as a short-hand expression for any kind of shift in the production function. Thus slowdowns, speed-ups, improvements in the education of the labor force, and all sorts of things will appear as "technical change." (p. 312)

In its most succinct form, the aggregate formulation combines various types of capital into a single total $K$, and different types of labor into a single $L$. Once formed, they are treated as substitutes, implying that the same amount of output can be produced by different combinations of capital and labor.

The basic sources-of-growth model is derived from an aggregate production function which is assumed to exhibit constant returns to scale in capital and labor, and Hicks'-neutral productivity change as reflected in a shift term $A_{t}$. Under the further assumption that capital and labor are paid the value of their marginal products, the resulting $Y_{t}=A_{t} F\left(K_{t}, L_{t}\right)$ can be differentiated with respect to time to give the sources of growth equation:

$$
\stackrel{*}{y}=s_{K} \stackrel{*}{k}+s_{L} \stackrel{*}{\ell}+\stackrel{*}{a} .
$$

Dots over variables indicate rates of growth and time subscripts are dropped for ease of exposition. This formulation decomposes the growth rate of output into the growth rates of the inputs, weighted by their respective output elasticities (as proxied by income shares), and the growth in the productivity with which the inputs are used (total factor productivity, or TFP). The former is interpreted as a movement along the production function and the latter, as a shift. Both processes are assumed to occur smoothly. All the elements of this equation except the last term can be measured using data on prices and quantities, or assumptions about parameters like capital depreciation. This allows the productivity variable to be measured as a residual. 
There is no specific provision for the contributions of education or skills in the basic formulation. This issue was addressed by Jorgenson and Griliches (1967), who proposed a version of the production function that allowed for different types of labor, differentiated by worker characteristics like education, which have different wage rates and marginal products. The production function then becomes $Y=A F\left(K, L\left(H_{1}, \ldots, H_{N}\right)\right)$, where the $H_{i}$ 's are the hours worked in each of the $N$ categories, total hours are $H=\Sigma_{i} H_{i}$, and $L(\bullet)$ is a function that aggregates the $N$ groups into an index of total labor input. The growth rate of $L$ is the shareweighted contribution of each group's hours to total hours, where the $s_{H i}$ are each group's share of total labor income:

$$
\stackrel{*}{\ell}=\stackrel{*}{h}+\sum_{i=1}^{N} s_{H i}(\stackrel{*}{h}+\stackrel{*}{h})=\stackrel{*}{h}+q_{L C} \text {. }
$$

The growth rate of labor input is thus the sum of the growth rate of total unweighted hours plus the labor composition effect, $q_{L C}$. The associated growth equation is then

$$
\stackrel{*}{y}=s_{K} \stackrel{*}{k}+s_{L} \ddot{h}^{*}+s_{L} \stackrel{q_{L C}}{q^{*}}+\stackrel{*}{a} .
$$

The variable $q_{L C}$ records the effect on output of a shift in worker hours among groups with different output elasticities (cum factor shares), and is positive when the composition of the labor force shifts toward higher productivity groups. In practice, multiple worker characteristics are included in the index.

It is this framework that produced the BLS estimates, cited in the introduction, that show $q_{L C}$ accounted for only $7 \%$ of labor productivity growth in the private business sector over the period 1995 to 2007. The overall composition effect is dominated by the education effect, and the $7 \%$ estimate reflects the combined effect of the increase in the wage share of the educated (its weight in $q_{L C}$ ) and the growth rate of educational attainment as reflected in the H's. Estimates reported at the end of this paper also show an acceleration in the $q_{L C}$ effect in the 1970s, and a slowdown in the late 1990s averaging 7\% for the period 1995-2007.

\section{A Choice of Parables}

The relatively small contribution of education in recent years seems inconsistent with the growth of the knowledge economy. Indeed, Hanushek and Woessmann (2015) begin their book on The Knowledge Capital of Nations with the statement that "knowledge is the key to economic 
growth" and go on to note the positive correlation between educational attainment and income per capita in a cross-sectional comparison of countries. Acemoglu and Autor (2012) have also expressed their reservations, as noted above. Since it is hard to imagine the complex technologies and capital of the digital revolution being operated with a work force equipped with only the most rudimentary cognitive skills and knowledge, it therefore seems appropriate to examine the sources-of-growth framework more closely to see what features of the model might lead to that result.

Solow himself recognized the simplification involved when he began his classic 1957 paper with "it takes something more than a 'willing suspension of disbelief' to talk seriously of the aggregate production function”, and, in his 1987 Nobel Laureate Lecture, "I would be happy if you were to accept that [growth accounting results] point to a qualitative truth and give perhaps some guide to orders of magnitude” (Solow (1988), p. xxii). Writing in defense of the aggregate approach, Samuelson (1962) argues that it is a parable whose purpose is insight building (more on this below).

Parables are neither inherently right nor wrong, just more or less useful for illustrating some underlying truth. The growth accounting model has enjoyed great success for its insights into the general contours of economic growth. However, the aggregate model may be more successful in describing overall economic growth than in characterizing structural economic change and the implied role of education. The problem is that some of the assumptions underlying the neoclassical model require a particularly large suspension of disbelief. The first is the one-sector nature of the aggregate production function, $Y_{t}=F\left(K_{t}(\bullet), L_{t}(\bullet), t\right)$. The single product, $Y_{t}$, is a macroeconomic surrogate for the many products actually produced, and the surrogate aggregate production is a methodological parable for summarizing the complex processes that contribute to their production. This formulation is a useful, indeed, essential, part of the conceptual framework that underpins the aggregate circular-flow of products and payments that characterize the macro economy. However, its usefulness is questionable for addressing issues concerning changes in the structure of the flows that make up the aggregate -in the composition of $Y_{t}$-- and the corresponding changes in the allocation of resources that are evident in Figure 2.

A more general representation of the structure of production is needed in order to deal with these structural issues. A step in this direction can be made by formulating the production 


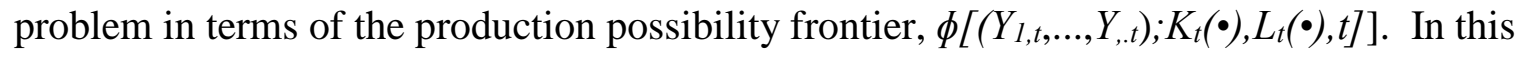
formulation, the collection of outputs at any point in time, $\left(Y_{1, t}, \ldots, Y_{m, t}\right)$, is produced by aggregate capital, $K_{t}(\bullet)$, whose components are categories of capital identified by type and industry of use, and aggregate labor, $L_{t}(\bullet)$, whose components are categories of labor identified by their characteristics (including education) and industry of use. The technology shifter $t$ is included to allow for increases in the efficiency with which labor and capital are used, although individual efficiency parameters $A_{i . t}$ might be used instead (or the factor augmentation equivalents). Underlying the PPF are separate industry production functions for each sectoral output, $Y_{i . t}=F^{i}\left(K_{i . t}(\bullet), L_{i . t}(\bullet), t\right) .^{3}$

The multiproduct way of looking at the structure of production has an important implication for studying the importance of skills and education: a movement along the production possibility frontier not only changes the composition of output, it shifts the composition of the inputs required to produce the output. With these shifts come changes in the required composition of labor skills. This means that a change in the mix of skills may occur without technical change, as for example, when the movement along $\phi$ is caused by changes in the structure of consumer preferences or changes brought about by a shift in the pattern of global trade, or by non-unitary income elasticities. Indeed, aggregate output along the PPF may be unchanged. ${ }^{4}$

Then there is the question of technical change. This is represented in the conventional aggregate formulation as a shift in the production function holding inputs constant (or, a similar shift in the PPF). This convention implicitly views all technical change in terms of increases in the productivity of the input base, or "process innovation". This kind of innovation has made important contributions to economic growth during the course of the information revolution, but it is not the only kind of technical change, nor necessarily the most important. Innovation in new or improved products has also played a central role in the revolution. ${ }^{5}$

\footnotetext{
3 The assumptions required to move from the individual sectoral production functions, $Y_{i, t}=F i\left(K_{i, t}(\bullet), L_{i, t}(\bullet), t\right)$, to an exact form of the aggregate production function, $Y_{t}=F\left(K_{t}(\bullet), L_{t}(\bullet), t\right)$, are very restrictive.

${ }^{4}$ The sources-of growth equation (1) is, formally, a Divisia Index (Hulten (1973)). A movement along the PPF frontier $\phi$ from one point to another involves line integration that does not change the value of the output index (the invariance property).

${ }^{5}$ Data from the National Science Foundation’s Business R\&D and Innovation Survey (BRDIS) suggest that process-oriented business $\mathrm{R} \& \mathrm{D}$ is a small share of the total, accounting for only $15 \%$ of the $\$ 224$ billion in domestic R\&D paid for by companies (Wolfe (2012)). The rest is for product development, though some of the new products
} 
Product innovation changes the mix of outputs $\left(Y_{1 . t}, \ldots, Y_{m . t}\right)$ over time. Improved goods appear and ultimately displace their older counterparts, others drop out because of a lack of demand, while new goods enter the market. In the process, a new vector appears, $\left(Y_{1, t+l t}, \ldots, Y_{m+k, t+1}\right)$, with a product list expanded by $k$ to allow for new items. The list of individual product functions is expanded accordingly, but with $Y_{i . t+1}=0$ for displaced goods. The individual production functions for the new or improved goods may have a different set of skill requirements than those they displace. Evidence suggests that this was, indeed, the case during the information revolution, during which the growth in digital-economy goods has led to increases in the demand for more cognitively complex skills sets. However, it is important to note that, while the technology for producing the new goods became more complex and required more complex skills, the main impetus behind the increased demand for these skills was product innovation and not skill-biased process innovation.

Two further suspensions of disbelief are also needed. The first involves the assumption that the capital and labor are paid the values of their marginal products, thus allowing income shares to be used as a proxy for the underlying output elasticities in the sources-of-growth formulation. This is a very strong assumption, mainly defensible as a macroeconomic approximation. Prices may well deviate from marginal products due to monopolistic pricing, labor market rigidities, discrimination, and cyclical fluctuations in economic activity. Moreover, the marginal social return to education may exceed the marginal private return implied by market wages because of externalities of the type noted by Lucas (1988), a point elaborated in a subsequent section.

Second, the existence of separate aggregate labor and capital entities, $L(\bullet)$ and $K(\bullet)$, and of a unique $q_{L C}$, requires the assumption of weak separability in the aggregate production function. This, in turn, requires the marginal rate of substitution between one type of labor and another to be independent of the amount and composition of aggregate capital (Hulten (1973)). This is a mathematical proposition, but in economic terms, it means that if a worker in a lower education category acquires a higher degree in pursuit of a wage premium, output will increase without any change in capital or technology. This is problematic because those workers with

are inputs to the production process (capital-embodied technical change, for example, or improved materials). The fraction of R\&D devoted primarily to new consumer goods is not reported. 
higher educational attainment often do, indeed usually, end up in jobs or occupations with more complex technological requirements and capital. Simply educating more people will not, all else held equal, necessarily result in a significant increase in output, a point that will be elaborated in the activity-analysis model developed in the section that follows.

\section{The Activity-Analysis Approach to Production}

\section{A. The Model}

A close examination of the neoclassical model of production thus suggests that it may not capture the full effects of education buried in the underlying complexity of "reality". Indeed, one of the founders of the neoclassical aggregate approach, Paul Samuelson, has indeed ”insisted” in his 1962 paper on "Parable and Realism in Capital Theory” that

"capital theory can be rigorously developed without using any Clark-like concept of aggregate 'capital', instead relying upon a complete analysis of a great variety of heterogeneous physical capital goods and processes through time. Such an analysis leans heavily on the tools of modern linear and more general programming and might therefore be called neo-neo-classical. It takes the view that if we are to understand the trends in how incomes are distributed among different kinds of labor and different kinds of property owners, both in the aggregate and in the detailed composition, then studies of changing technologies, human and natural resources availabilities, taste patterns, and all the other matters of microeconomics are likely to be very important” (p. 193).

This is essentially the view taken in this paper. But, he goes on to say:

“At the same time in various places I have subjected to detailed exposition certain simplified models involving only a few factors of production. Because of a Gresham's Law that operates in economics, one's easier expositions get more readers than one's harder. And it is partly for this reason that such simple models or parables do, I think, have considerable heuristic value in giving insights into the fundamentals of interest theory in all its complexities” (p. 193),

The tension between the two perspectives over the appropriate level of analysis is central to the objections against the neoclassical production function and the concept of aggregate capital raised during the Cambridge Controversies of the 1950s and 1960s (Harcourt (1969)). ${ }^{6}$

\footnotetext{
6 Opposition to the aggregate production function and the neoclassical view of economic growth has a long history, and is by no means limited to the Cambridge Controversies. It is also present in the literatures on organizational theory, the importance of institutions in economic history, and in Schumpeterian analysis. Nelson and Winter (1962) provide an in-depth analysis of the evolutionary nature of the process of economic growth that focuses on the firm and its activities, and the skills and competence of its workers. The activity analysis model sketched in this paper is rooted in this view of the firm.
} 
Given these questions and those that have been raised about the size of the neoclassical labor composition effect, it seems reasonable to take a closer look at the micro foundations of the aggregate production framework, essentially disaggregating it to get at its "primitive” activityanalysis level. When approached at this foundational level, many of the issues raised in this paper can be addressed, particularly those involving the way labor-skills interact with capital to make educational attainment necessary for many activities. The “old fashioned” activityanalysis model is well-suited to this task. ${ }^{7}$

Where the neoclassical model offers a succinct and mathematically viable way of summarizing the supply-side of the economy, the activity analysis is neither succinct nor mathematically convenient. It does provide a more detailed look into the underlying processes of growth and the shifting demands for the various skills and types of capital required by different production techniques. It treats the firm and its various activities, not the aggregate production function, as the fundamental unit of analysis for studying the shifting demand for different types of labor and capital.

An activity is defined in this paper as an operational segment of a firm that has an identifiable output or outcome produced by a technique that specifies a certain mix of inputs. What gives the activity-analysis parable its distinctive feature is the assumption that the inputs are combined in a fixed proportion. This assumption implies that there is no substitution among inputs, so each input is necessary for the activity, and it thus contrasts strongly with the assumption of input substitutability in the neoclassical parable. A firm may operate several activities simultaneously, as, for example, both production and non production (or overhead) activities, or the activities of multiple establishments within the firm, each producing a different product. In light of the model of Acemoglu and Autor (2011), it is worth noting that the way the labor input functions within an activity may involve a specific set of tasks requiring a specific set of skills. ${ }^{8}$

\footnotetext{
7 Activity analysis has had a long and honorable, though somewhat neglected, history. It was well positioned, in the early 1950s, to become the dominant supply-side paradigm for the economy. The 1951 Cowles Commission conference volume, Activity Analysis of Production and Allocation, edited by Tjalling C. Koopmans, contains papers authored by four future Nobel Laureates in Economics. Yet, it was neoclassical growth theory that prevailed over the next two decades.

${ }^{8}$ In their framework, a task is defined as a unit of work activity that produces an output. This use of the term "activity" in the context of job performance differs from the way an activity is conceived of in this paper, which involves a fixed-proportions technology that may encompass many separate tasks and types of input. However, the task-based activity of Acemoglu and Autor and the production-based activity approach are mutually consistent and
} 
The following example illustrates the issues involved. A given amount of earth can be moved using different techniques: one technique uses a few skilled operators equipped with expensive bulldozers, the other uses many manual workers each equipped with cheap shovels. In the aggregate representation of these different techniques, the "neoclassical” form of the technology for earth-moving would be $Y=A F\left(K_{H}, K_{L}, H_{S}, H_{U}\right)$, or the factor augmentation equivalent (the capital subscripts denote "higher technology bulldozers" and "lower technology shovels", and "skilled” and “unskilled” for the labor subscripts). In order to speak of aggregate capital, $K$, and labor, $L$, this production function must have the previously noted separable form, which in this case is $Y=A F\left(K\left(K_{H}, K_{L}\right), L\left(H_{S}, H_{U}\right)\right)$. The different types of labor are substitutable among each other within the labor aggregate $L(\bullet)$, as are the different types of capital within $K(\bullet)$, and the aggregates themselves are substitutable along an isoquant connecting $K$ and $L$. The isoquant $Q Q$ shown in Figure 3A allows for this substitution, which occurs as the movement along the isoquant from $A$ to $B$ as relative factor prices change from $a a$ to $b b$. The broken Lshaped lines represent two activities that use different techniques for producing the same amount of output, $Y$, and illustrate the putty-putty model of neoclassical analysis in which the isoquant is the envelope of the various activities. ${ }^{9}$

As portrayed in Figure 3A, activity analysis is consistent with the aggregate production function as long as aggregate capital is treated as a homogeneous malleable entity that represents forgone consumption valued at investment cost. While this is a useful macroeconomic way of looking at capital and technology -- Samuelson’s surrogate production function -- it glosses over the technical differences between shovels and bulldozers and the skill differences between the workers. It is therefore not a helpful framework for studying how the choice of technique affects the demand for skilled labor.

Figure 3B illustrates the "clay-clay" version of activity analysis in which different types of capital work with the requisite labor and skills and cannot be substituted across or within an activity. This implies that the separate inputs should not be combined using the $K\left(K_{H}, K_{L}\right)$ and

can operate simultaneously, although the former is used to motivate aggregate skill biased technical change, with the implication that the BLS sources-of growth estimates understate the role of complex-skill development, while activity analysis in this paper is used to motivate the "necessary input" framework that also implies that the role of complex-skill development is understated, though it operates through a different channel.

9 There is a putty-clay variant in the model which applies when investments are irreversible in the short run and capital can only be changed as it depreciates. 
$L\left(H_{S}, H_{U}\right)$ parings of the aggregate production function approach, but instead by the functional pairings $a\left(K_{L}, H_{U}\right)$ and $b\left(K_{H}, H_{S}\right)$. This is represented in Figure 3B by the broken L-shaped lines showing the two techniques for producing the same amount of output, $Y$. However, while both techniques produce the same kind (and amount) of output, the inputs on the axes refer to different types of capital and labor. One implication is that the factor price lines $a a$ and $b b$ refer to different input prices. Moreover, the strict complementarity of the techniques implies that the ratios of the marginal products of the different types of capital and labor are not well-defined and variations in the wage-rental cannot affect the input ratio. Thus, if the wage rate increases, there can be no substitution of capital for labor within a technique.

An important implication for this paper is that a shift in techniques from $a\left(K_{L}, H_{U}\right)$ to $b\left(K_{H}, H_{S}\right)$ cannot occur without a shift from unskilled to skilled workers and from less to more technologically sophisticated capital (which is to say, there is no substitution along the isoquant of a surrogate production function). In this particular case, a deficiency of skilled workers will slow or prevent the adoption of the $b\left(K_{H}, H_{S}\right)$ technology. It is also possible, in a more sophisticated rendering of the model, that a deficiency of workers with a particular skill set could induce innovation designed to compensate for the deficiency (the Habakkuk thesis), but the larger point is that in order for a firm to actually operate the activity $b\left(K_{H}, H_{S}\right)$, access to both $K_{H}$ and $H_{S}$ in the right proportions is necessary.

Figure 3C adds yet another complication. The activities in the first two figures represent different techniques for producing the same type of output. This is not a good assumption to apply to all activities in an era with a high rate of product innovation because switching from one quality, or model, of output to another often involves a switch in the way the goods are produced and in the inputs required. For example, in summarizing their study of new IT-enhanced machinery, Bartel, Ichniowski, and Shaw (2007) make the following points:

"First, plants that adopt new IT-enhanced equipment also shift their business strategies by producing more customized valve products. Second, new IT investments improve the efficiency of all stages of the production process by reducing setup times, run times, and inspection times. The reductions in setup times are theoretically important because they make it less costly to switch production from one product to another and support the change in business strategy to more customized production. Third, adoption of new IT-enhanced capital equipment coincides with increases in the skill requirements of machine operators, notably technical and problem-solving skills, and with the adoption of new human resource practices to support these skills.” 
The ability to customize output to suit the needs of the buyer represents an important change in product quality, and is linked, in this case, to increased skill requirements. The advent of the automatic teller machine, a labor saving device from the standpoint of production, is another example of how the quality of a product was also improved, in this case by making money accessible at all times of day or night. These examples are illustrated in Figure 3C by activityspecific output indexes.

\section{B. Aggregation and Dynamics}

The activities as portrayed in Figures 3A, 3B, and 3C illustrate the logic of the activity-analysis model. From an operational standpoint, activities are generally combined to form a larger set that constitute the production plan of a firm. In formal terms, the technology of a firm $j$ can be characterized at any point in time by the activity set $\mathrm{A}_{j, t}$, whose elements are the totality of activities it operates $\left\{a_{i, j, t}\left(K_{i, j, t}, H_{i, j, t}, M_{i, j, t}\right)\right\}$. An output or outcome is associated with each activity, although much of the output is delivered to other activities within the firm (e.g., overhead and different stages of production along an assembly line). The vector $M_{i, j, t}$ is added to allow for the presence of intermediate goods produced and used within the firm, but also the intermediate inputs acquired externally. The set $\left\{a_{i, j, t}\left(K_{i, j, t}, H_{i, j, t}, M_{i, j, t}\right)\right\}$ is thus a disaggregated representation of the firm's technology, but it is not, strictly speaking, a neoclassical production function relating total output to aggregated inputs. ${ }^{10}$

The firm is the organizational entity responsible for choosing the appropriate mix and level of activities for $\mathrm{A}_{j, t}$ from a larger set of possible techniques. Selecting the right mix and level of activities is an essential organizational function of the firm, and once the selection has been made, the capital requirements of the firm $\left\{K_{i, j, t\}}\right\}$ and staffing needs $\left\{H_{i, j, t}\right\}$ are determined. Prescott and Visscher (1980) point to the acquisition and proper use of human capital as centrally important for the success of an organization, and Bloom and Van Reenen (2007) have pointed to the importance of good managers and management practices. The role of human agency can sometimes get lost in the formal mathematical presentation of the various models.

\footnotetext{
10 As previously noted, the conditions for exact functional aggregation are extremely stringent. The analytics of the aggregation of multiple outputs in the presence of intermediate goods can be found in Hulten (1978). And, other aspects of the aggregation problem makes exact aggregation even more difficult (e.g., the separability also noted previously).
} 
Firms can be grouped into industries for purposes of analysis, though again, there are aggregation issues. Indeed, many are similar to those encountered when aggregating the internally generated "output" of activities within firms, but with the additional complication posed by different ways of classifying industries (the company versus establishment problem). However, these difficulties are not germane to the main interests of this paper, so we simply group firm-level activities into industry-level activities (however industry is defined), and then into an aggregate economy-wide activity set $\mathrm{A}_{t}$ whose elements include the totality of all activities, $\left\{a_{i, t}\left(K_{i, t}, H_{i, t}, M_{i, t}\right)\right\}$. The significance of this formulation for the problem at hand is that, at any point in time, the total capital requirements $\left\{K_{i, t}\right\}$ and staffing needs $\left\{H_{i, t}\right\}$ of the economy are determined by the choice of activities at the firm level, the diversity of activities across firms in an industry, and the diversity of industries in the larger economy.

The mix of activities and skills can and does change over time, as witnessed by the structural changes in the economy evident in Figures 1 and 2. This structural change is the visible result of the shifting composition of the aggregate activity set $\mathrm{A}_{t}$ occurring in response to the revolution in information and communication technology and the globalization of the world economy. New or improved products have made older goods obsolete, new processes and activities within firms have replaced older techniques, and new forms of product distribution have displaced older outlets. New firms and industries have appeared in this process of creative destruction, while older industries have declined and firms exited their industry or reinvented themselves. The changes occurring in $\mathrm{A}_{t}$ have also changed the demands for labor and capital. This has meant a larger demand for those higher-order skills, occupations, and education that have been made necessary by the information revolution. One of the major implications of the activity analysis framework, as it is set out above, is that the observed structural changes could not have occurred without the parallel development of the appropriate skills. In other words, the “necessary input” way of looking at structural change implies that skill development and the associated contribution of education is an organic part of the dynamic evolution of the changing economy.

Education also contributes to this evolution in another way. Much of the underlying innovation originates within firms through activities like $R \& D$, product design, and strategic planning. Much of the innovation that drives the dynamics of firms and the economy comes in the form of product innovation. These activities are education-intensive (Nelson and Phelps 
(1966)), and some of the innovation may come in response to chronic deficits in some skill areas (e.g., process automation). And, even when innovation does not originate in the firm, it is implemented and sustained by the efforts of its management. The activities, and the people that operate them, endogenize the innovation process (as in Romer (1986, 1990)), and, in turn, create a demand for the skills and occupations of the digital economy.

However, it is also important to stress (once more) that education by itself is not sufficient for creating more output growth. Moreover, it should also be noted that, while technical change and globalization have shifted the structure of activities toward those that require more complex skills, there are still activities that do not require higher levels of educational attainment (indeed, the large majority do not, as we will see in a subsequent section). The activity-analysis framework focuses on the necessity of the appropriate skills for the activity at hand, and this applies to the full range of activities in operation at any point in time, not just to those involving more complex labor skills.

\section{Activities and the Measurement of GDP}

An output is associated with each activity in a firm's activity set, $\mathrm{A}_{j, t}$, even though some are shadow outputs delivered to other activities within the firm. The value of the output sold externally (intermediate and other) can be measured using market transaction prices and the resulting revenue divided between deliveries to final demand and deliveries to intermediate demand. This yields the accounting equation $P_{i, t} Q_{i, t}=P_{i, t} Q_{i, t}^{D_{i, t}} \sum_{j} P_{i, t} Q^{M}{ }_{i, j, t}$, where $Q^{M}{ }_{i, j, t}$ is the delivery of the intermediate good from activity $i$ to the other activities, and $Q^{D}$ i,t is the external output delivered to final demand (for a one product firm). GDP is then defined as the summation across deliveries to final demand, giving $G D P_{t}=\sum_{i} P_{i, t} Q^{D_{i, t}}$.

On the input side, the cost of the inputs acquired externally -- labor, capital, and intermediate inputs - can be summed to arrive at total cost, and this can be divided into the value added of labor and capital, on the one hand, and the cost of acquiring intermediate inputs on the other: $C_{i, t}=P_{i, t}^{K} K_{i, t}+P_{i, t}^{L} L_{i, t}+\sum_{j} P_{j, t} Q^{M}{ }_{i, j, t}$. Gross Domestic Income is then the sum of the value added components, yielding: $G D I_{t}=\sum_{i} P^{K}{ }_{i, t} K_{i, t}+\sum_{i} P_{i, t}^{L} L_{i, t}$. Because the production and use of intermediate inputs cancel out, the value of aggregate output equals the value of aggregate factor income in each year, or, $G D P_{t}$ equals $G D I_{t}$. 
Of what significance is this accounting result for the issues of importance to this paper? It can be used to show that the growth accounting results of BLS do not depend on the existence of Solow's aggregate neoclassical production function. The sources-of-growth decomposition in equation (1) can be derived directly from the accounting identities of the preceding paragraph that equates GDP and GDI, but only when each side of this equation is expressed in "real” inflation-corrected terms (that is, when nominal prices are replaced with a base-year price index). When this is done, $G D P_{0, t}=\Sigma_{i} P_{i, 0} Q_{i, t}^{D_{i, t}}$ and $G D I_{0, t}=\Sigma_{i} P_{i, 0}^{K} K_{i, t}+\sum_{i} P_{i, 0}^{L_{i, t}} L_{i}$ where, $G D P_{0, t}$ and $G D I_{0, t}$ are real GDP and real GDI in year $t$ expressed in base-year prices. The base-year final demand price indexes, $P^{D}{ }_{i, 0}$, and base-year factor prices, $P^{K}{ }_{i, 0}$ and $P^{L}{ }_{i, 0}$, may have different time trends, and real $\mathrm{GDP}_{0, t}$ does not in general equal real $\mathrm{GDI}_{0, t}$, except in the base year. In other years, there is a wedge between the two that gives rise to a version of TFP. In its most general formulation, TFP is defined as the ratio of output per unit of total factor input, or equally, the ratio of real GDP to real GDI.: $A_{t}=G D P_{0, t} / G D I_{0, t}=\sum_{i} P_{i, 0} Q_{i, t}^{D_{i, t}} /\left[\sum_{i} P_{i, 0}^{K} K_{i, t}+\sum_{i} P_{i, 0}^{L} L_{i, t}\right]$. This, indeed, was the way growth accounting was formulated prior to Solow's 1957 paper (Hulten (2001)). ${ }^{11}$ The larger point is that the neoclassical production function approach is not necessary for the BLS-like growth accounting results to be obtained, and it is not the only way the TFP results can be interpreted, particularly those relating to the role of skills and education.

\section{Structural Changes in Education, Skills, and Occupations}

The preceding sections are largely technical in nature. The three sections that follow are empirical, and make use of the existing literature to examine the evidence on the trends in labor and capital to see if they are consistent with the predictions of the activity-analysis framework. The third of these sections shows the results of a version of the sources-of-growth account expanded to include intangible capital, and interprets the role of skills and education in light of the "necessary input” activity-analysis model.

\footnotetext{
11 What Solow did in his 1957 paper was to provide an interpretation of the growth accounting ratio by assuming the existence of an aggregate production function, $Y=A F(K, L)$, in which case $A_{t}=\mathrm{Y}_{t} / F\left(K_{t}, L_{t}\right)$. Solow's formulation of TFP is thus a special case of the more general formulation, one that summarizes and interprets the messy world of the full activity set, $\mathrm{A}_{t}$, but also one that loses sight of the messy way activities are organized and the way different inputs and their characteristics actually relate to one another.
} 


\section{A. Educational Attainment}

A look back over the last half century reveals major changes in the educational status of the U.S. population and work force. In 1960, only 40\% of the non-institutionalized population 25 or older had a high school degree or more, and only 8\% had college degree, according to 2015 CPS estimates; by 1985, these figures rose to $74 \%$ and $19 \%$; and by 2013 , almost $90 \%$ of this population had at least a high school degree, and more than $30 \%$ had at least a bachelor's degree. Similar numbers are reported in Valletta (forthcoming) on an employment basis. From 1980 to 2015, the portion of the employed with a high school degree or more went from $80 \%$ to $90 \%$; those with a four-year college degree went from $16 \%$ to $25 \%$; and those with a graduate degree went from $7 \%$ to $14 \%$. In any case, there has been a significant and on-going increase in educational attainment over the last three to five decades. Valletta also reports that the increase may have slowed in recent years. ${ }^{12}$

Many have noted that the growth in educational attainment coincides with a growth in the return to a college education (Acemoglu and Autor (2012) provide an excellent in-depth look at the data and survey of the associated literature). The estimates of Goldin and Katz (2010) show that the college wage premium relative to a high school degree increased from $40 \%$ in 1960 to almost $60 \%$ in 2005, and they attribute this growth to an imbalance in the demand for educated workers and the supply. ${ }^{13}$ Valletta's estimates of wage-premia are, again, consistent with the Goldin-Katz results, and they also point to a very large premium for graduate degrees (particularly professional and doctorate degrees). A rising wage-premia is also consistent with

\footnotetext{
12 While the quantity of education, as measured by the growth in degrees, has increased significantly, it should be recognized that formal schooling is not identical to education or human capital accumulation (e.g., family and peer environment also matter). There is also an open question about the quality of education. The 2013 NAEP report card suggests that the literacy and numeracy skills of U.S. 12th graders has been stagnant in recent years, and that a majority of students are stuck at skill levels that are rated below proficient, with one-quarter of students below "basic" in reading and one-third below "basic" in mathematics. Similar results were reported in the 2015 NAEP assessment. Indeed, the proportions have not changed significantly since the inception of the NAEP (1992 for reading and 2005 for math). American students also lag those in many other countries. The 2013 Programme of International Assessment of Adult Competencies (PIAAC) found that the U.S. ranked 16th of 23 countries in adult literacy, 21st of 23 countries in numeracy, and 14th of 23 in problem solving. However, the same study also found that the U.S. stood out from other countries in its propensity to reward those with the highest skills (Broecke et al. (forthcoming)).

13 The Goldin-Katz college wage premium reflects an average across those with college degrees. This should not be confused with the marginal return to further education. Heckman et al. (2016) find that ability is a major component of observed educational outcome differentials and argue that going to college is not necessarily a wise choice for everyone.
} 
an increase in the derived demand for more highly educated workers in conjunction with a lagged response in the supply of college-educated people. Limited substitution possibilities between skilled and under-skilled workers in many of the emerging activities of the knowledge economy were a likely contributing factor. ${ }^{14}$

\section{B. Task-Related Skills and Education}

Structural changes in the distribution of task-related skills have received a great deal of attention in recent years, following the publication of Autor, Levy, and Murnane (2003). The authors distinguish between non-routine and routine skills, and manual versus analytical skills, and show that the non-routine analytical skills have grown in importance in the last five decades at the expense of the others. An updated version of these results, from Autor and Price (2013), found that the gap between non-routine cognitive and interpersonal skills and the other categories (routine and manual) increased from an index of 100 in 1960 to around 150 in 2010. In studying the college and graduate school wage premia associated with these different skill categories, Valletta finds a growing premium for all skills, with the largest premia for non-routine cognitive skills. The premia have increased over time, but have slowed in recent years.

There is an intuitive similarity between the patterns observed for higher education and higher-order skills, but the actual situation is more nuanced. Skill levels and education are not identical, a point often made in the literature. ${ }^{15}$ Skills are appropriately defined as adeptness with respect to a specific task (complex or not), while education is a process though which information is transferred and capabilities developed. Moreover, it is widely recognized that education is only one of the channels through which skills are developed, and that other factors like family background and peer environment, and idiosyncratic factors like health and cognitive ability, also matter.

\footnotetext{
14 The importance of educational externalities noted by Lucas (1988) is worth repeating here. Because of spillover externalities, the social return to education exceeds the private wage premium, and it is the total return that affects economic growth.

15 Cappelli (2015) observes that, "The standard classification of job requirements into 'knowledge, skills, and abilities' reminds us that education, which has served as a proxy for skills in most discussions, only maps onto part of the "knowledge" category, leaving the other attributes of job requirements out of the picture. There are many important reasons for being concerned about education, but seeing it as the equivalent of skill is certainly a mistake.”
} 
Data from the recent BLS Occupational Requirements Survey (ORS) support this view. The ORS develops a metric “Specific Vocational Preparation” (or SVP) that measures the time spent in skill development, which is described as the time spent in pre-employment training (formal education and certification and training programs), prior work experience in related jobs, and the time needed in the job itself to get to average performance (Gittleman, Monaco, and Nestoriak (forthcoming)). When these three types of preparation are cross-classified with the actual time requirements, the authors report that post-employment training and prior work experience are the most important components of SVP, with formal education in third place. However, for those jobs requiring the highest levels of skills, formal education is in a distant second place and behind prior work experience.

That study presents another important finding: those jobs requiring a B.A. degree or more account for less than $25 \%$ of all jobs (or less than $30 \%$ using the O*NET educational classification). It is interesting to note, in this regard, that only about 30 percent of the adult population has one of these degrees. Gittleman et al. also report that only 15 percent of jobs were classified in the most complex category. This serves as a warning against an excessive focus on higher education and complex skills, as well as a reminder that a broad range of skills is needed for economic activity, and that those at the lower end are both economically and numerically significant.

However, while this evidence seems to downplay the importance of a college education, the ORS study also finds that higher educational attainment is positively correlated with the complexity of skills and choice of professional occupation. This comes from the part of the study that looks at three mental and cognitive dimensions of job requirements: "task complexity”, "work control”, and "regular contacts". The first is broken into categories ranging from very complex tasks to very simple; the second into categories ranging from very loose to very close control; the third ranges from structured and very structured regular contacts to very unstructured. One of the most interesting features of this analysis is the high correlation among the higher skill segments of "task complexity”, “work control”, "regular contacts” dimensions, as well as the higher skill components of educational attainment, SVP, and choice of occupation. The fit is not perfect, but a high degree of collinearity does suggest that certain regularities exist that characterize different jobs. Thus, while education is but one of several channels through which skills and expertise are developed, the collinearity suggests a link between higher 
education and higher-order skill sets. The ORS also reports data on the wage-skill gradient similar to those found in Autor and Handel (2013) and Goldin and Katz, and by Valletta. Those in jobs with the highest task complex skills, the loosest degree of work control, and the least structured interactions all earn significantly higher wages than those at the other end of these scales. ${ }^{16}$

\section{Science, Technology, Engineering, and Mathematics}

Developments in science and technology are at the heart of the information revolution and thus merit a close look. This is all the more important because STEM activities evoke highly educated workers in research labs and computer facilities working on complex problems. However, the 2013 study by Rothwell argues that there are actually two STEM economies. One is a "professional" STEM economy associated with higher education and high levels of compensation, which "plays a vital function in keeping American businesses on the cutting edge of technological development and deployment. Its workers are generally compensated extremely well”. The other STEM economy "draws from high schools, workshops, vocational schools, and community colleges", and its members are "less likely to be directly involved in invention, but they are critical to the implementation of new ideas, and advise researchers on the feasibility of design options, cost estimates, and other practical aspects of technological development”. They "produce, install, and repair the products and production machines patented by professional researchers, allowing firms to reach their markets, reduce product defects, create process innovations, and enhance productivity".

Hanson and Slaughter (forthcoming) report that employment in the STEM professions has grown from around 3.5\% of the total hours worked in the U.S. in 1993 to around 6\% in 2013. In the broader view of STEM employment, Rothwell finds that 20\% percent of all 2012 jobs required a "high level of knowledge in any one STEM field" based on his index of the STEM

16 Much attention has been given to the importance of cognitive skills. However, recent research has also focused on the demand for non-cognitive skills, which include characteristics like self-discipline, perseverance, attentiveness, dependability, orderliness, persistence in the pursuit of long-term goals, and the ability to get along with others. Non-routine interpersonal skills were found by Autor and Price to have grown in importance relative to non-routine cognitive skills. Deming (2017) also shows that the labor market increasingly rewards social skills, and that jobs with high social skill requirements have shown greater relative growth throughout the wage distribution since 1980. He also observes that the strongest employment and wage growth has occurred in jobs that require both high levels of hard cognitive skills and soft social skills. The importance of non-cognitive skills is also noted in Lundberg (2013), Heckman and Kautz (2012). 
skill content of various occupations (up from around 8\% in 1900 and around 15\% in 1950). He also finds that half of the STEM jobs are "available to workers without a four-year college degree".

The domestic supply of new professionals to the first STEM "economy" has expanded in recent years. NCES data on STEM degrees completed show an expansion from 1990 to 2011 in B.A.s (39\% for engineering, a doubling for science/math), in M.A.s (90\% for engineering, $87 \%$ science/math), and in Ph.D.s (76\% for engineering, 60\% science/math)). This domestic growth in STEM skills has not, however, been sufficient to satisfy the demand for STEM workers. Hanson and Slaughter report that foreign-born workers currently account for one-half of the hours worked in STEM occupations among prime-age workers with an advanced degree, up from one-quarter in the 1990s and one-fifth in the 1980s. In other words, immigration is an important source of skills that supplements domestic efforts at skill development.

\section{Structural Change in the Composition of Capital}

The activity-analysis model of Section IV ties labor of various skills to the capital appropriate to those skills. The preceding section has documented the shift in the distribution of skills toward more complexity, as well as the occupations that embody them, and linked these shifts to the growth in educational attainment. This section documents a parallel shift on the capital side, consistent with the complementarity between capital and labor in the activity-analysis view of production.

The last 40 years have seen a significant shift in the composition of investment in the U.S. private business sector, away from tangible structures and equipment towards investments in intangible capital. There has also been a shift within tangible capital toward information technology (ICT) equipment. Intangible capital is highly firm-specific and produced in-house, and includes such categories as computerized information, innovative property like R\&D, and economic competencies (the categories proposed by Corrado, Hulten, and Sichel $(2005,2009)$ ). The first is mainly software, and comprises $13 \%$ of the overall intangible investment rate in 2010. Innovative property is a diverse group that includes not only the conventional National Science Foundation (NSF) type of R\&D, with its orientation to science and technology, but also other important forms of R\&D such as investments in artistic originals (books, movies, and music), development of new financial products, and architectural and engineering designs. The 
largest category of intangible capital is economic competencies, divided into brand equity (advertising, marketing, customer support), firm-specific human capital (worker training), and organizational structure, a rather amorphous grouping that includes investments in management and human resource systems, strategic planning, and management consulting. Many of these intangibles are the source of a firm's intellectual property.

The rate of investment in these intangibles over the period 1977 to 2010 is shown in Figure 4. The rate rose significantly over the period, starting at just over 8\% in 1977 and reaching just under $14 \%$ by the end of the period. The growth in importance of this type of capital is in sharp contrast to the declining rate of tangible capital investment shown in the figure, falling from the $11 \%$ to $13 \%$ range in the late 1970 s to around $8 \%$ by the end of the period (9.6\% in 2007, the last year before the Great Recession). The overall trends reflect the decision by many companies to move up the global value-chain to higher valued added activities like product design and marketing, all overhead activities, as well as the decline in tangible capital-intensive manufacturing. It is interesting to note that the overall rate of investment, tangible and intangible combined, remained relatively constant over the period, heightening the importance of structural change for understanding dynamic changes in the economy, and not just the growth of the economy.

When the rate of investment of ICT capital is broken out of total tangible capital in Figure 4 and shown separately, the ICT investment share is seen to have doubled between the mid 1970s and mid 1980s, then remained relatively constant, and then surged again in the late 1990s before falling back to its post-1980 trend (while the intangible rate continued to increase, though at a much slower pace). However, these patterns do not tell the whole story. While the investment rate of the non-ICT tangible category (not shown) has declined in relative importance in recent years, this category of capital is far from technologically stagnant. The digital revolution has found its way into such non-ICT tangible capital goods as autos and trucks, medical equipment, and machine tools (recall the 2007 paper by Bartel et al.), as well into some structures. The extent to which technology is embodied in capital is hard to determine, but my own rather dated estimate found a large embodiment effect for the period 1947-1983: the unadjusted annual growth rate of equipment, as estimated by the BLS, was $4.4 \%$, while the quality-adjusted rate calculated in the paper was 7.3\% (Hulten 1992)). The BEA does make a 
quality adjustment to some types of equipment, with those for computing equipment and software being notably large.

The time path of the intangible investment rate is shown again in Figure 5, with the 1960 value indexed to 100 in order to facilitate comparison with education and skill indicators. The four variables included in this figure -- the rate of intangible investment, "expert” industry employment, the college wage premium, and the Autor-Price gap between non-routine cognitive and non-cognitive skills, each indexed to an initial 100 - all show upward trends. The visible association of these trends over the course of the information revolution is far from dispositive, but it does not require much of Solow's suspension of disbelief to recognize in the aggregate data that which is readily apparent at the level of the research lab, corporate headquarters, or the plant floor.

\section{Growth Accounting and Activity Analysis}

\section{A. The Sources of Growth Model with Intangible Capital}

What does the importance of intangible capital, skills and education in the activity analysis parable imply for the sources of growth? While neoclassical and activity-analysis models operate through different economic mechanisms, the sources-of-growth estimates associated with the former are consistent with those of the latter, as discussed in Section IV. The conventional BLS sources of growth estimates can thus be interpreted in light of either model. When this is done, the activity analysis reinterpretation assigns a much greater role to education.

The sources-of-growth estimates of this paper are shown in Table 1. Unlike the conventional BLS growth accounts, the estimates of this table include the list of intangibles studied by Corrado, Hulten and Sichel (2009). ${ }^{17}$ The expanded growth rate of output per hour in the U.S. Private Business sector over the period 1948 to 2007 (the last year before the financial crisis) is decomposed into the contributions of tangible and intangible capital per labor hour, labor composition, and TFP growth. ${ }^{18}$ The top panel shows the percent contribution of the first

\footnotetext{
17 The estimates shown in Table 1 are based on Corrado and Hulten (2010) and updates. When the list of inputs is expanded to include the stock of intangible capital, the concept of output must be expanded to include the corresponding output of intangible investment.

18 When interpreting the capital-labor ratios in Table 1 in terms of activity analysis, it is important to recognize that the table involves the ratio of different types of capital to total labor input; in the case of intangible capital, R, this is $\mathrm{R} / \mathrm{L}$. This is not the ratio relevant for the activity analysis interpretation, which is, instead, the ratio of intangible
} 
four to the growth in output per hour, measured as the growth rate of each multiplied by its income share, with TFP measured as a residual. It is apparent that the sources of growth changed appreciably over the course of the whole period. The contribution of intangible capital increased almost threefold (10\% to 27\%) from the first sub-period, 1948-1973, to the last, 19952007. ICT capital experienced a similar proportionate increase (4\% to $13 \%$ ) and the combined contribution was $40 \%$ in the last period. TFP's contribution fell from $60 \%$ to $42 \%$. Labor composition enjoyed a "boom" in the middle period that saw its contribution increase three-fold to $17 \%$, but this fell back to $7 \%$ during the last period. ${ }^{19}$

Figure 6 presents these trends in an annual time series format. The annual growth rate of output per hour, shown at the top of the figure, follows a generally declining, but volatile, path. The same is true of the TFP growth path below it, with the volatility of the former reflected in the latter (no surprise, since TFP is measured as a residual). The growing importance in knowledge capital deepening via intangibles is evident, increasing to the point where its contribution to growth rivals that of the declining TFP trend. The relatively small contribution of labor quality is also shown, indicating an upward surge in the 1980s, before falling back during the 1990 s.

The neoclassical interpretation of Table 1 and Figure 6 suggests an important role for capital deepening via the substitution of capital for labor, and a relatively small role for labor composition change. The activity-analysis interpretation suggests a different view of the matter, one that interprets the same patterns in terms of the structural change in the composition of activities. In this alternative view, the large contributions of intangible and ICT capital per worker hour evident in this table (and in Figure 6) were enabled by the growth in educational

capital to the labor actually used with intangible capital, $\mathrm{R} / \mathrm{L}_{\mathrm{r}}$. The former is related to the latter by the equation $\mathrm{R} / \mathrm{L}$ $=\left(\mathrm{R} / \mathrm{L}_{\mathrm{r}}\right)\left(\mathrm{L}_{\mathrm{r}} / \mathrm{L}\right)$. In pure activity analysis, $\mathrm{R} / \mathrm{L}_{\mathrm{r}}$ is given by the technology, and any growth in the ratio is zero. Growth in $\mathrm{R} / \mathrm{L}$, as seen in Table 1, must therefore reflect a change in the employment ratio, $\mathrm{L}_{\mathrm{r}} / \mathrm{L}$. The data on employment patterns in Figure 2 show significant growth in the relative shares of both expert service and overhead organizational services, suggesting that this indeed may have happened. These types of jobs are precisely those most likely to be used with intangible capital, so it is not implausible that much of the observed change in R/L was largely due to an increase in $\mathrm{L}_{\mathrm{r}} / \mathrm{L}$. However, this is only a surmise, since there is no tight match between different types of intangible of capital (which are quite heterogeneous) and the requisite types of labor skills (also heterogeneous). Moreover, $\mathrm{R} / \mathrm{L}_{\mathrm{r}}$ itself may well have increased during the ICT Revolution as superior types of intangible and ICT capital entered production and enabled new activities or, alternatively, as the mix of activities shifted to those with a greater degree of capital intensity.

${ }^{19}$ Given the prominence of R\&D spending in discussions of innovation, it is interesting to note the relatively small (6\%) role played by scientific “NSF” R\&D from 1995 to 2007. 
attainment, skills, and professional occupations. ${ }^{20}$ Indeed, the latter were necessary for the growth of the former, implying that education's role in the growth process was almost certainly much larger than the rather small amount assigned to it by the aggregate approach of neoclassical growth accounting.

The contribution of education may be even greater still, since some of its effects may be suppressed in the residual measure of TFP. There are at least three channels through which this can happen. One of the most important for this paper is the spillover externalities associated with an educated workforce identified in Lucas (1988). In his model of economic development, educated workers interact in ways not captured by private wage premia, leading to a social return to education that exceeds the private return. The increase in GDP associated with the excess return is not captured by the measured contribution of labor growth or the labor composition term, and is thus suppressed into the TFP residual (which is thereby overstated).

Much the same can be said of R\&D spillovers (Romer (1986, 1990)). By its nature, knowledge is non-rival and subject to diffusion, and the social rate of return may therefore exceed the private rate of return to the original innovator. Hall et al. (2010) review the literature on the relative private and social returns to $R \& D$ investment and conclude that the latter is “almost always estimated to be substantially greater than the private returns (p. 1073).” This, too, is suppressed into the TFP residual. Finally, Acemoglu and Autor $(2011,2012)$ show that task-oriented skill-biased technical change may be suppressed into the TFP residual. Where the conventional Solow model assumes that technical change has the Hicks'-neutral form and is thus without a factor bias, they show that when there is a bias that favors skilled workers and occupations, education's observed contribution to growth may be understated and measured TFP overstated.

\footnotetext{
20 Beaudry et al. (2016) appeal to the link between knowledge capital and college-educated labor as an explanation for a slowdown in the demand for higher-order skills and higher education after 2000, which they term the "Great Reversal in the Demand for Skill and Cognitive Tasks". They attribute the "reversal" to the slowing growth in ICT equipment and software (which are treated as a general purpose organization technology within the firm). They use a neoclassical optimization approach in their modeling of the link, and a more limited concept of intangible capital. The focus of this paper is on the contribution of education and skills to economic growth and productivity, using a much broader conception of knowledge capital (all intangible capital and ICT equipment) and stocks as well as flows. The data underlying Figure 6 of this paper indicate that the contributions of ICT equipment and software did decline after 2000, but also there was not much of a decline in the contribution of the rest of non-software intangible capital (although there was a large amount of cyclical variability).
} 


\section{B. The Sources of Growth: Firm Dynamics}

The statistics of Table 1 portray growth as a rather "bloodless" and formulaic process in which inputs and technology are mathematically transformed into output. The actual process of growth is anything but "bloodless", involving, as it does, the birth and death of firms and the struggle for survival and success of incumbent firms. Since this paper has emphasized the importance of structural changes in the micro activities that underpin the aggregate flows of inputs and output, and emphasized the importance of human agency in organizing and staffing these activities, a closer look at the firm dynamics that underpin the evolution of these activities is warranted.

The industries in the private economy are typically composed of both large and small firms, as well as older and newer ones. Research has shown that all firms are not equal when it comes to growth, and that those that are relatively young and rapidly growing are responsible for a disproportionate amount of net job creation (Haltiwanger et al. (2010); Strangler, (2010); and Sadeghi et al., (2012)). Strangler finds that, in a typical year, fast-growing young firms (“gazelles”) made up less than $1 \%$ of all companies, but generated about $10 \%$ of all new jobs. Sadeghi et al. report that the $0.5 \%$ of all companies classified as "high-growth firms" between 2008 and 2011 were responsible for a third of all gross job creation among firms whose employment increased over the period. Moreover, smaller firms are also an important source of R\&D spending. According to NSF data, small companies with fewer than 500 employees in 2009 had an average R\&D investment rate that was three times that of the largest firms and employed a third of R\&D workers, despite their much smaller sales and overall employment.

Hathaway and Litan (2014) highlight the importance of firm births and deaths. They note that one new business is born approximately every minute, and that another business fails every eighty seconds. They go on to show that jobs are both created and destroyed in the process, with net job creation of 600 thousand jobs in 2012. This “churn”, as they call it, suggests a Schumpeterian view of firm dynamics in which growth is neither smooth nor formulaic. It is a process in which good decisions and good luck tend to be rewarded and inadequate or obsolete business models, punished. By implication, human agency and competence in the formulation and execution of business models, and in making the investments needed to enhance a firm's capabilities and products, are critical in order for new entrants to become gazelles and for incumbents to prosper. 
The churning of firms through entry and exit has implications for economic growth. It is an important mechanism through which new products and processes enter the economy, and through which new markets are developed. Intangible capital and higher-order skills, cognitive and non-cognitive, play a major role in this process. The most important asset of a successful new enterprise is the capability (though not necessarily higher education) of those who start and guide its development, who manage its operation, and who foster technological and organizational innovation. The study by Kerr and Kerr (2017) shows that these key ingredients are sometime "imported", as witnessed by the finding that around a quarter of all entrepreneurs in 2008 were immigrants, up from some 17\% in $1995 .^{21}$ They also report that $38 \%$ of new firms had at least one immigrant entrepreneur, and that the share of employees in new firms who were immigrants was $26 \%$.

\section{Summary and Conclusions}

The neoclassical and activity-analysis models offer different windows on the role of education in the process of economic growth, two ways of looking into the same complex processes involved. The activity-analysis perspective provides insights into the role of skill-development and education in the functioning of the economy, a perspective that is important because workers with different skills and levels of education are not free-standing ingredients in a recipe for making aggregate output. They are the necessary ingredients of the specific recipe for which they are needed, in conjunction with the capital and other inputs required in order to operate the activity at a given scale. A deficit in either the requisite skills or the associated capital limits the operation or growth of those activities. To repeat, it is hard to imagine today's emerging knowledge economy operating with a work force in which less than half the workers had a high school degree, and less than $10 \%$ had a college degree.

What the future actually holds for continued economic growth and employment is a matter of great conjecture. Powerful technological and global forces continue to shape the world of work, and one can only guess where they will lead in the "Race against the machine" of Brynjolfsson and McAfee (2014). Looking backward at the data, the importance of the high skill-occupation-education nexus for past economic growth seems well established. Looking

21 The notion of "entrepreneur" used here is defined as someone who is among the top three initial earners in the new business. Kerr and Kerr also report that their findings are roughly comparable to those in the large literature they review, though a few report appreciably lower percentages. 
ahead, it may well be that robots will ultimately make most human work skills obsolete. It may be that education will increasingly be seen as preparation for a productive life of leisure. But for now, it seems reasonable to conclude that a strong educational system - one that provides a full range of skill-development - remains an essential part of America's economic prosperity. As Levy and Murnane (2013, p. 5) put it: “For the foreseeable future, the challenge of 'cybernation' is not mass unemployment but the need to educate many more young people for the jobs computers cannot do". 


\section{REFERENCES}

Acemoglu, Daron, and David Autor, “What Does Human Capital Do? A Review of Goldin and Katz's The Race between Education and Technology, Journal of Economic Literature, 50:2, 2012, 426-463

Acemoglu, Daron, and David Autor, "Skills, tasks and technologies: Implications for employment and earnings," Handbook of Labor Economics 4, 2011, 1043-1171.

Autor, David H., "Skills, education, and the rise of earnings inequality among the 'other 99 percent'," Science, Vol. 344 no. 6186, May 2014, 843-85. DOI: 10.1126/science.1251868

Autor, David H., and Michael J. Handel. 2013. "Putting Tasks to the Test: Human Capital, Job Tasks and Wages.” Journal of Labor Economics, 31(2, pt.2), S59-S96.

Autor, D.H. and B. Price, The Changing Task Composition of the US Labor Market: An Update of Autor, Levy and Murnane (2003), MIT working paper, June 21, 2013.

Autor, David H., David Dorn, and Gordon H. Hanson, “The China syndrome: Local labor market effects of import competition in the United States”, American Economic Review. 103, no. 6, 2013, 2121-68.

Autor, D. H., F. Levy and R. J. Murnane, “The Skill Content of Recent Technological Change: An Empirical Investigation,” Quarterly Journal of Economics, November, Vol. 118(4), 2003, 1279-1333.

Bartel, Ann P., Casey Ichniowski, Kathryn L. Shaw, "How Does Information Technology Affect Productivity? Plant-Level Comparisons of Product Innovation, Process Improvement, and Worker Skills," Quarterly Journal of Economics, November 2007, 122, 4, 1721-1758.

Beaudry, Paul, David A. Green, Ben Sand, "The great reversal in the demand for skill and cognitive tasks”, Journal of Labor Economics, Economics, 2016, vol. 34, no. 1, pt. 2, S199-S247.

Bloom, N. and J. Van Reenen, "Measuring and Explaining Management Practices Across Firms and Nations,” Quarterly Journal of Economics, Vol. 122 (4), 2007, 1351-1408.

Broecke, Stijn, Glenda Quintini, and Marieke Vandeweyer, "Wage inequality and cognitive skills: Reopening the debate”,paper prepared for the NBER/CRIW conference Education, Skills, and Technical Change: Implications for Future U.S. GDP Growth, Bethesda, Maryland, October 16-17, 2015 (forthcoming in conference volume).

Brynjolfsson, E. and A. McAfee, Race Against The Machine: How the Digital Revolution is Accelerating Innovation, Driving Productivity, and Irreversibly Transforming Employment and the Economy, Digital Frontier Press, January 29, 2014.

Bureau of Labor Statistics, Education and training outlook for occupations, 2012-22, Division of Occupational, Employment Projections, http://www.bls.gov/emp/ep_edtrain_outlook.pdf,

Bureau of Labor Statistics, Trends in Multifactor Productivity, 1948-81, Bulletin 2178, USGPO, Washington D.C., September 1983, and updates.

Cappelli, Peter, "Skill Gaps, Skill Shortages, and Skill Mismatches," ILR Review, vol 68(2), 2015, 251290. 
Corrado, Carol A. and Charles R. Hulten, “How Do You Measure a Technological Revolution?,” American Economic Review, May, 2010, 99-104.

Corrado, Carol A. and Charles R. Hulten, "Innovation Accounting”, in "Measuring Economic Progress and Economic Sustainability,” in D.W. Jorgenson, J.S. Landefeld, and P. Schreyer, eds., Studies in Income and Wealth, vol. 72, The University of Chicago Press for the National Bureau of Economic Research, Chicago, 2014, 595-628

Corrado, C., C. Hulten and D. Sichel, "Intangible Capital and Economic Growth,” The Review of Income and Wealth, Vol. 55 (3), 2009, 661-685.

Cowles Commission, Activity Analysis of Production and Allocation, Proceedings of a Conference, edited by Tjalling C. Koopmans, in cooperation with Armen Alchian, George B. Danzig, Nicholas GeorgescuRoegen, Paul A. Samuelson, and Alert W. Tucker, The Cowles Commission, John Wiley \& Sons, Inc., New York, and Chapman \& Hall, Limited, London, 1951.

Deming, David J., "The Growing Importance of Social Skills in the Labor Market," The Quarterly Journal of Economics, vol 132(4), 2017, 1593-1640.

Digest of Educational Statistics, Table 502.30, National Center for Educational Statistics, 2014 https://nces.ed.gov/programs/digest/d14/tables/dt14_502.30.asp

Gittleman, Maury, Kristen Monaco, and Nicole Nestoriak, The Requirements of Jobs: Evidence from a Nationally Representative Survey, paper prepared for the NBER/CRIW conference Education, Skills, and Technical Change: Implications for Future U.S. GDP Growth, Bethesda, Maryland, October 16-17, 2015 (forthcoming in conference volume).

Goldin, Claudia and Lawrence F. Katz, The Race between Education and Technology, Belknap Press, 2010.

Hall, Bronwyn, Jacques Mairesse, and Pierre Mohnen, "Measuring the Return to R\&D," Handbook of the Economics of Innovation, Chapter 24, B. H. Hall and N. Rosenberg (eds.), Elsevier-North Holland, 2010, 1033-1082.

Haltiwanger, J. C., R. S. Jarmin and J. Miranda, "Who Creates Jobs? Small vs. Large vs. Young,” "Who Creates Jobs? Small vs. Large vs. Young”, Review of Economics and Statistics, 2013, 347-361.

Hanson. Gordon, and Matthew J. Slaughter, High Skilled Immigration and the Rise of STEM Occupations in US Employment, paper prepared for the NBER/CRIW conference Education, Skills, and Technical Change: Implications for Future U.S. GDP Growth, Bethesda, Maryland, October 16-17, 2015 (forthcoming in conference volume).

Hanushek, Eric A., and Ludger Woessmann, "The role of cognitive skills in economic development," Journal of Economic Literature 46, no. 3, 2008, 607-668.

Hanushek, Eric A., and Ludger Woessmann, The Knowledge Capital of Nations: Education and the Economics of Growth, 2015.

Harcourt, G. C., "Some Cambridge Controversies in the Theory of Capital”, Journal of Economic Literature, Vol. 7, No. 2 (Jun., 1969), 369-405 
Haskel, Jonathan, Robert Z. Lawrence, Edward E. Leamer, and Matthew J. Slaughter, 'Globalization and U.S. Wages: Modifying Classic Theory to Explain Recent Facts”, Journal of Economic Perspectives, Volume 26, Number 2 (Spring) 2012, 119-140.

Hathaway, Ian, and Robert E. Litan, "Declining Business Dynamism in the United States: A Look at States and Metros”, Economic Studies, The Brookings Institution, May 2014.

Heckman, James J., John Eric Humphries, and Gregory Veramendi, Returns to Education: The Causal Effects of Education on Earnings, Health and Smoking, NBER Working Paper 22291, May 2016, http://www.nber.org/papers/w22291.

Heckman, James J., and Tim Kautz, "Hard evidence on soft skills." Labour economics, 2012, 451-464.

Hulten, Charles R., "Divisia Index Numbers," Econometrica, Vol. 41, No. 6, November 1973, 1017-25.

Hulten, Charles R., "Growth Accounting with Intermediate Inputs," Review of Economic Studies, Vol. 45, No. 3, October 1978, 511-518.

Hulten, Charles R., "Growth Accounting when Technical Change is Embodied in Capital," American Economic Review, Vol. 82, No. 4, September 1992, 964-980.

Hulten, Charles R., "Total Factor Productivity: A Short Biography," in New Developments in Productivity Analysis, Charles R. Hulten, Edwin R. Dean, and Michael J. Harper, eds., Studies in Income and Wealth, vol. 63, The University of Chicago Press , Chicago, 2001, 1-47.

Hulten, Charles R., Stimulating Economic Growth through Knowledge-based Investment, OECD Science, Technology and Industry Working Papers, 2013/02, OECD Publishing.

Jorgenson, Dale W. and Zvi Griliches, "The Explanation of Productivity Change," Review of Economic Studies, 34, July 1967, 349-83.

Kerr, Sari Pekkala, and William R. Kerr, “Immigrant Entrepreneurship”, in Measuring Entrepreneurial Business: Current Knowledge and Challenges, John Haltiwanger, Erik Hurst, Javier Miranda and Antoinette Schoar, eds. Studies in Income and Wealth Number 75, Chicago, Chicago University Press for the NBER, 2017, 187-249.

Levy, Frank, and Richard Murnane, Dancing with Robots: Human Skills for Computerized Work, Third Way, June 1, 2013. http://content.thirdway.org/publications/714/Dancing-With- ubble-64671ed

Lucas, Robert E. Jr., "On the Mechanics of Economic Development," Journal of Monetary Economics, 22, 1988, 3-42.

Lundberg, Shelly, “The College Type: Personality and Educational Inequality,” Journal of Labor Economics, Vol. 31. No. 3, July 2013, 421-441

Nakamura, Leonard, "What is the U.S. Gross Investment in Intangibles? (At Least) One Trillion Dollars a Year!” Federal Reserve Bank of Philadelphia Working Paper No. 01-15, $2001 .$.

National Assessment of Educational Progress, 2013, The Nation's Report Card, Are the nation's twelfthgraders making progress in mathematics and reading, 2013. Also, the Nation's Report Card, Math and Reading scores at Grade 12, 2015 
National Center for Education Statistics (NCES), Digest of Economic Statistics, 2015, Table 318.20, Bachelor's, master's, and doctor's degrees conferred by postsecondary institutions, by field of study: Selected years, 1970-71 through 2011-12.

National Science Foundation (2012), National Patterns of R\&D Resources: 2009 Data Update, National Center for Science and Engineering Statistics, Detailed Statistical Tables, NSF 12-321. June.

Nelson, Richard R., and Edmund S. Phelps, "Investment in Humans, Technological Diffusion, and Economic Growth." The American Economic Review 56.1/2 (1966): 69-75.

Nelson, Richard R., and Sidney G. Winter, An evolutionary theory of economic change An Belknap Press, August, 1982.

OECD, OECD Skills Outlook 2013: First Results from the Survey of Adult Skills, OECD Publishing, 2013. http://dx.doi.org/10.1787/9789264204256-en

OECD, PISA 2012 Results: Creative Problem Solving: Students' Skills in Tackling Real-Life Problems (Volume V), PI SA, OECD Publishing, 2014. http://dx.doi.org/10.1787/9789264208070-en

Prescott, Edward C., and Michael Visscher, “Organizational Capital,” Journal of Political Economy, 88, 3, 1980, 446-461.

Romer, Paul M., "Increasing Returns and Long-Run Growth," Journal of Political Economy, 94, No. 5, 1986, 1002-1037.

Romer, Paul M., “Endogenous Technological Change”, Journal of Political Economy, 98, 5. Part 2, October 1990, S71-S102.

Rothwell, Johnathan, The Hidden STEM Economy, Metropolitan Policy Program, Brookings, June 2013.

Ryan, Camille L., and Kurt Bauman, Educational Attainment in the United States: 2015: Population Characteristics, Current Population Reports, P20-578, March 2016

Sadeghi, A., J. R. Spletzer and D. M. Talan (2012), High Growth Firms, U.S. Bureau of Labor Statistics, unpublished, March 30.

Samuelson, Paul A., "Parable and Realism in Capital Theory: The Surrogate Production Function", The Review of Economic Studies, Vol. 29, No. 3, June, 1962, 193-206.

Solow, Robert M., “A contribution to the theory of economic growth”, Quarterly Journal of Economics, 70, February 1956, 65-94.

Solow, Robert M., "Technical Change and the Aggregate Production Function", Review of Economics and Statistics, 39, August 1957, 312-320.

Solow, Robert M., “We’d better watch out”, New York Times Book Review, July 121987.

Solow, Robert M., Growth Theory: An Exposition, Oxford University Press, New York and Oxford, 1988. 
Solow, Robert M., James Tobin, C. C. von Weizsacker, and M. Yaari, "Neoclassical Growth with Fixed Factor Proportions,” Review of Economic Studies, 33, 2, April 1966, 79-115.

Strangler, D. (2010), "High-Growth Firms and the Future of the American Economy, "Ewing Marion Kauffman Foundation, March, www.kauffman.org/newsroom/high-growth-firms-account-fordisproportionate-share-of-job-creation-according-to-kauffman-foundation-study.aspx.

U.S. Census Bureau, CPS Historical Time Series Tables, Table A.1 "Years of School Completed by People 25 Years and Over, by Age and Sex: Selected Years 1940 to 2015”, 2015.

Valletta, Robert G., Recent Flattening in the Higher Education Wage Premium: Polarization, Skill Downgrading, or Both?, paper prepared for the NBER/CRIW conference Education, Skills, and Technical Change: Implications for Future U.S. GDP Growth, Bethesda, Maryland, October 16-17, 2015 (forthcoming in conference volume).

Wolfe, R. M., "Business R\&D Performed in the United States Cost \$291 Billion in 2008 and \$282 Billion in 2009," InfoBrief, National Science Foundation, Social, Behavioral and Economic Sciences, NSF 12309, March 2012.

Zoghi, Cindy, Measuring Labor Composition: A Comparison of Alternate Methodologies, U.S. Bureau of Labor Statistics, Office of Productivity and Technology, June, 2007. 
Table 1

Sources of Growth in U.S. Private Business Sector (average of annual growth rates)

$\begin{array}{cccc}1948- & 1948- & 1973- & 1995- \\ 2007 & 1973 & 1995 & 2007\end{array}$

1. Output per hour

2.41

2.99

1.56

2.76

percentage point contribution to output per hour of:

2. Tangible capital

$\begin{array}{llll}0.65 & 0.76 & 0.52 & 0.64 \\ 0.23 & 0.11 & 0.28 & 0.36 \\ 0.32 & 0.65 & 0.24 & 0.27 \\ 0.42 & 0.30 & 0.39 & 0.74 \\ 0.06 & 0.01 & 0.07 & 0.15 \\ 0.19 & 0.15 & 0.16 & 0.32 \\ 0.10 & 0.08 & 0.07 & 0.17 \\ 0.09 & 0.07 & 0.09 & 0.15\end{array}$

R\&D)
a. ICT equipment
b. Non-ICT tangible capital

3. Intangible capital

a. Computerized information

b. Innovative property

(1) R\&D (NSF/BEA)

(2) Other (incl. non-NSF

c. Economic competencies

0.17

0.14

0.15

0.27

4. Labor composition

0.20

0.15

0.26

0.20

5. TFP

1.14

1.78

0.39

1.16

percent of total contribution to output per hour of:

$\begin{array}{lrrrr}\text { 2. Tangible capital } & 27 \% & 25 \% & 33 \% & 23 \% \\ \text { a. ICT equipment } & 10 \% & 4 \% & 18 \% & 13 \% \\ \text { b. Non-ICT tangible capital } & 13 \% & 16 \% & 13 \% & 10 \% \\ \text { 3. Intangible capital } & 17 \% & 10 \% & 25 \% & 27 \% \\ \text { a. Computerized information } & 2 \% & 0 \% & 4 \% & 5 \% \\ \text { b. Innovative property } & 8 \% & 5 \% & 10 \% & 12 \% \\ \text { (1) R\&D (NSF/BEA) } & 4 \% & 3 \% & 4 \% & 6 \% \\ \text { (2) Other } & 4 \% & 2 \% & 6 \% & 5 \% \\ \text { c. Economic competencies } & 7 \% & 5 \% & 10 \% & 10 \% \\ \text { 4. Labor composition } & 8 \% & 5 \% & 17 \% & 7 \% \\ \text { 5. TFP } & 47 \% & 60 \% & 25 \% & 43 \%\end{array}$

ICT refers to Information and Communications Technology Equipment, BEA to the Bureau of Economic Analysis, NSF to the National Science Foundation, TFP is Total Factor Productivity. Detail may not add up due to rounding error.

Source: Corrado and Hulten (2010). 


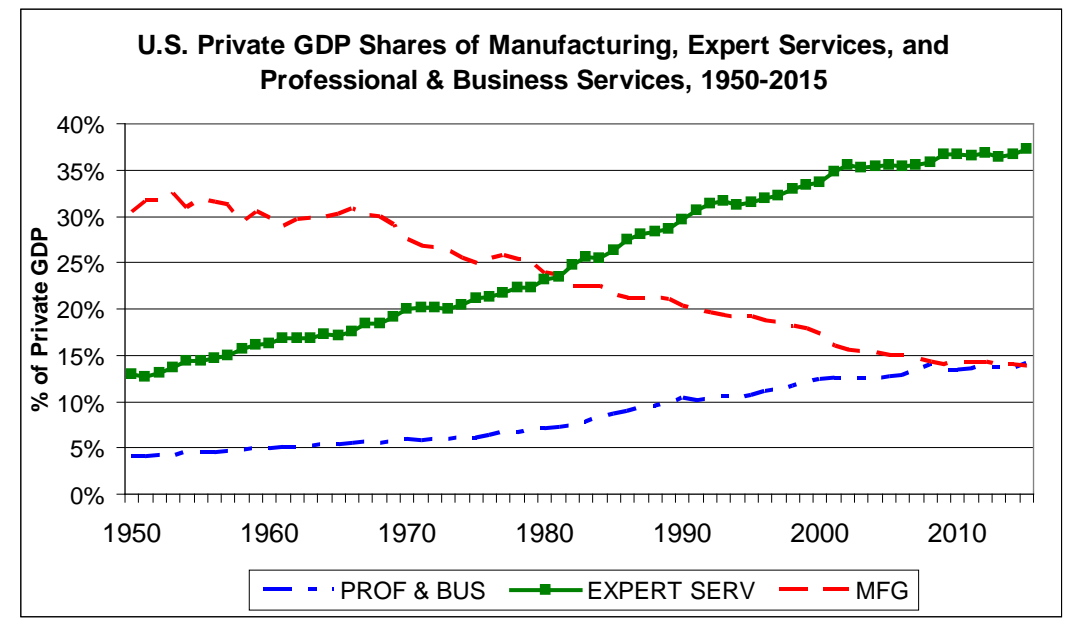

Figure 1

Source: Bureau of Economic Analysis, GDP-by-Industry, Industry Data, Value Added by Industry as a Percentage of Gross Domestic Product. The "expert” service sectors include the NAICS industries 51, 52, 54, 55, 61, and 62, and organizational service sectors 54, 55, and 56. MFG denotes manufacturing.

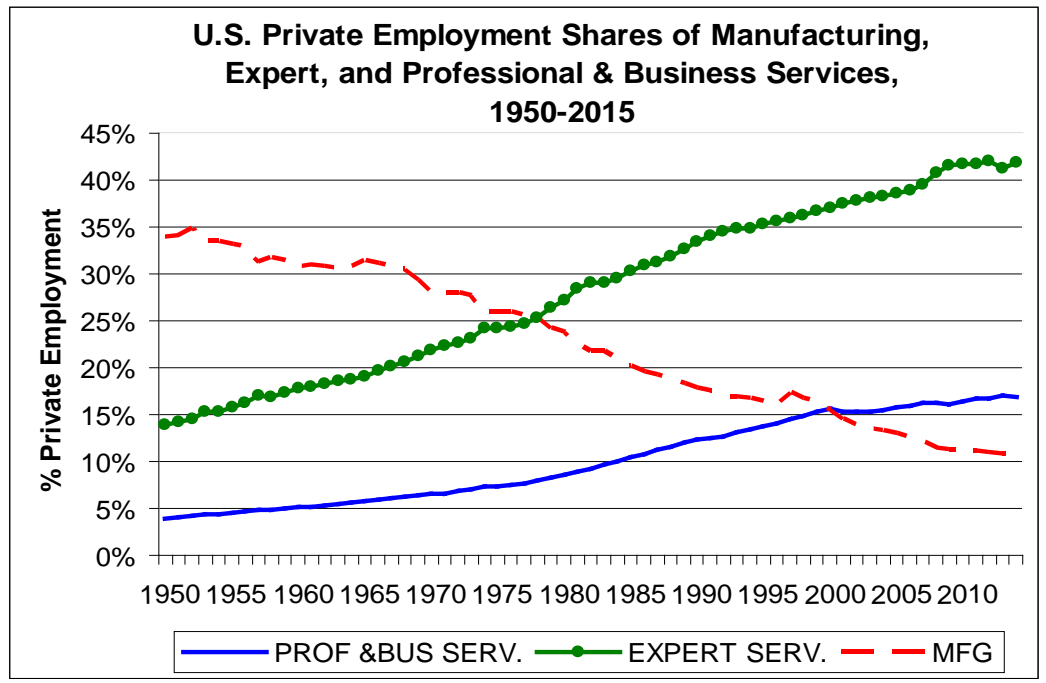

Figure 2

Source: Bureau of Economic Analysis, Industry Economic Accounts, from various parts of Table 6.5, Full-Time Equivalent Employees by Industry. See Figure 1. 


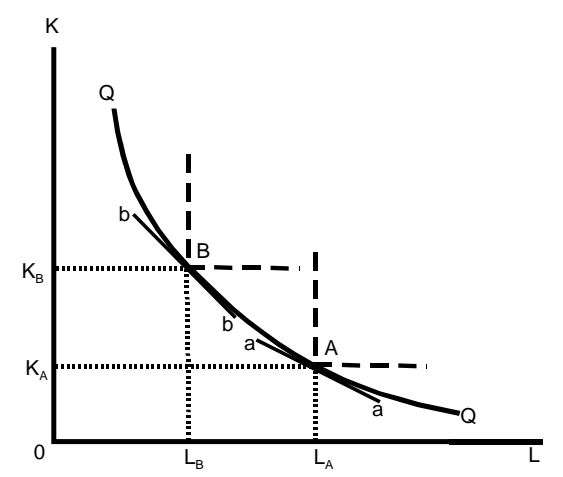

Figure 3A

Activity-Analysis Model

Two Activities and Malleable Inputs

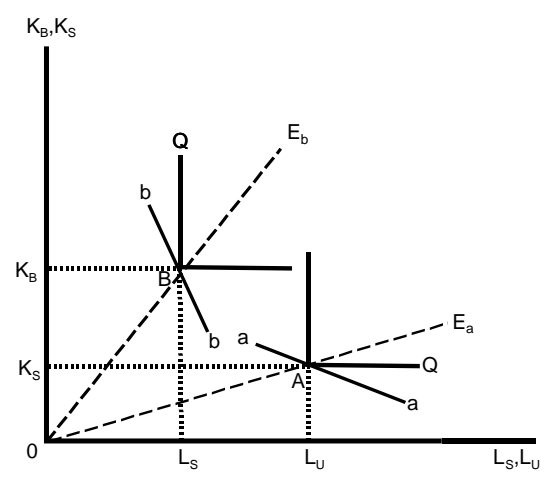

Figure 3B

Activity-Analysis Model

Two Activities and non-Malleable Inputs

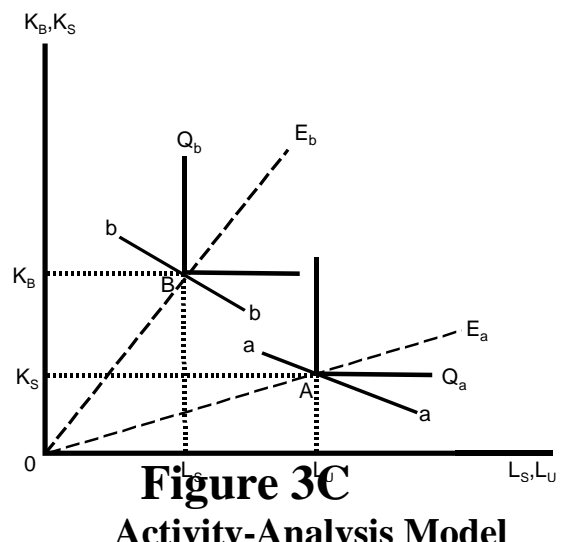

Activity-Analysis Model

Two Activities and Malleable Inputs plus Different Outputs

Investment in Intangible Capital, Tangible

Capital, and ICT as a Share of Private

Business GDP, 1977-2010

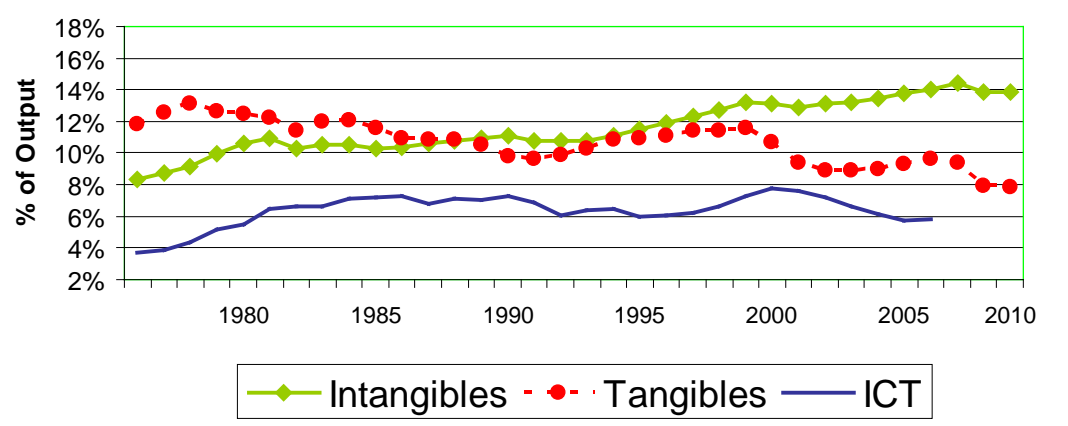

Figure 4

ICT is Information and Communications Technology Equipment

Source: Data Underlying Corrado and Hulten $(2010,2011)$. 


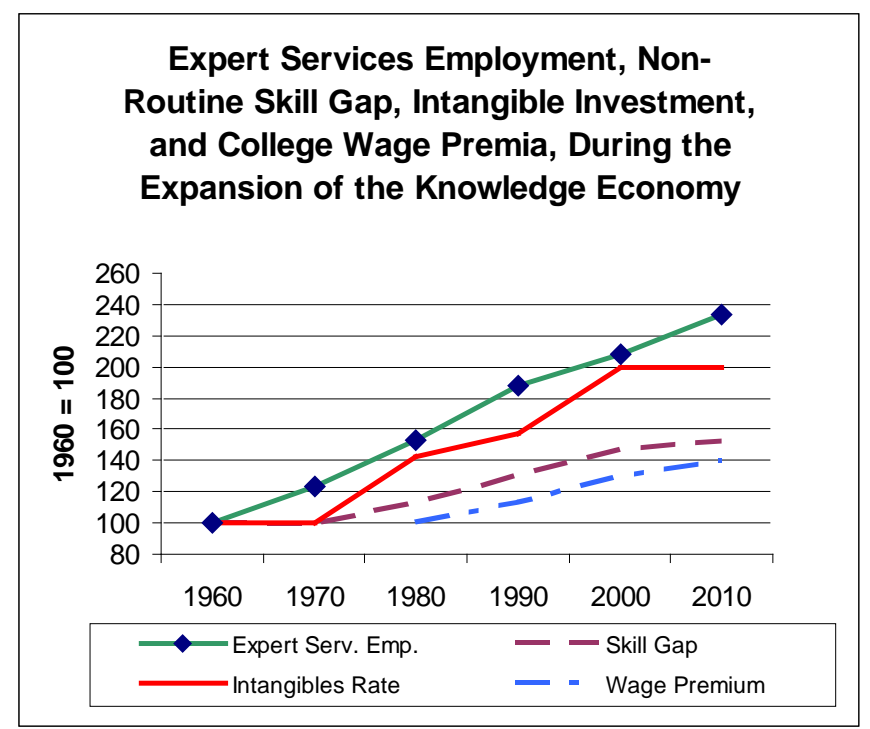

Sources:

Figure 5

1. Expert Service Industries Employment: Bureau of Economic Analysis, Industry Economic Accounts, Table 6.5, Full-Time Equivalent Employees by Industry (see Figure 2).

2. Skill Gap (ratio of non-routine cognitive and interpersonal indexes to the other indexes): Autor, D.H. and B.M. Price, "The Changing Task Composition of the US Labor Market: An Update of Autor, Levy, and Murnane (2003)”, MIT, June (2013).

3. Intangible investment rate; see Figure 4.

4. Wage premium based on Valletta (2016) (average of college-only and graduate premia, $1980=100$ )

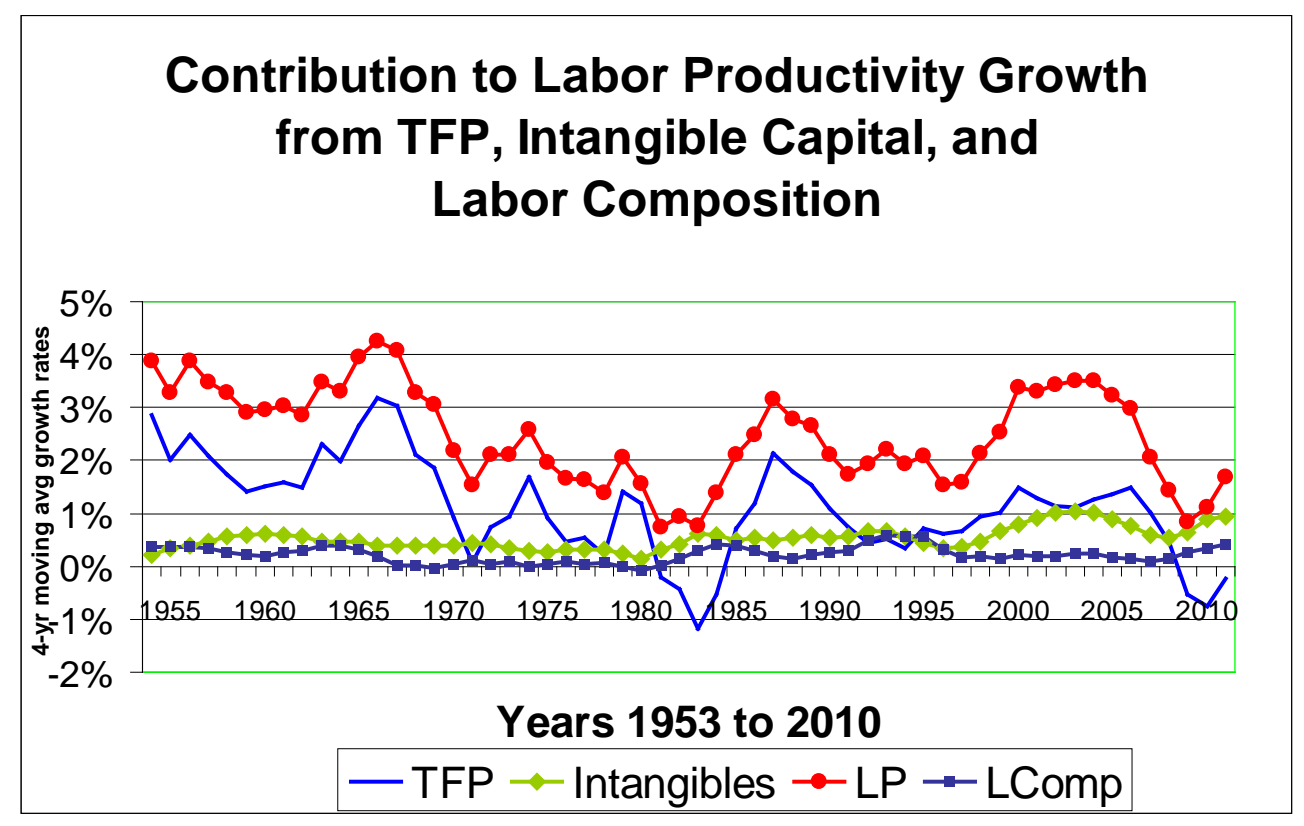

\section{Figure 6}

Source: Data Underlying Corrado and Hulten (2010, 2011).

(LP is output per hour, and LComp is the labor composition term) 